\title{
nature
}

\section{Good news for the year ahead}

\section{The traditional sport of guessing what will happen in the next twelve months is more cheerful this year than in the recent past. But anything could go wrong.

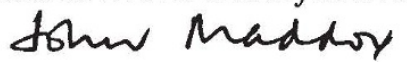

ThE best augury for 1987 is the return of Andreii Sakharov to Moscow. The next best is that Sakharov himself, while complaining that there are many others like him still kept against their inclinations in places even more uncomfortable than Gor'kii, should have praised the changes in Soviet society brought about, he says, by the new general secretary, $\mathrm{Mr}$ Mikhail Gorbachev. The tribute is all the more remarkable because Sakharov, a card-carrying truth-teller for four years isolated in a militarily-sensitive provincial city, could not within ten minutes of stumbling from an overnight train have founded his approval on personal observation. In any case, as Sakharov will soon discover, not much has changed as yet. The tyranny of the bureaucracy, the stultifying successor of the dictatorship of the proletariat, is still largely intact. What Sakharov is saying is no more than that he now shares with a small but influential band of his compatriots the belief that there is hope. Is that not grand?

Of course. But is it necessarily good? There are many outside the Soviet Union who consider Gorbachev's arrival to have been a misfortune; having learned how to handle septuagenarian emphysemiacs, people do not like seeing the goal posts moved. Yet the potential benefits of change far outweigh the inconvenience. The Soviet Union is a modern state with an antiquated economy which, some years, cannot feed even itself; who, elsewhere, could genuinely cry foul if it could be shamed into assisting the cause of development as other countries must, with cash and not simply with automatic rifles? The Soviet Union, forever talking world peace, repeatedly embarks on breathtakingly foolhardy military projects such as that, a decade ago and while the SALT II treaty was still fresh, to aim more than 200 SS-20 missiles at Western Europe; has the unrequited unilaterallySoviet ban on nuclear tests for the past 18 months been an attempt to show that somebody values butter more than guns?

History will no doubt explain, but there are more immediate benefits to be won. The virtual isolation for more than half a century of the intellectual community of the Soviet Union from that of the rest of the world has been a great disservice to both parts; will 1987 see a significant erosion of that artificial barrier? The prospects look good. And will the tendency to openness (see p. 9) persist? Sakharov's return to Moscow is a pointer in the right direction; evidently the Soviet authorities have reconciled themselves to the notion that there should be an open critic let loose to talk to whom he chooses, just as governments elsewhere have to put up with endless criticism - the Strategic Defense Initiative will not work, secretly selling arms to your public enemies is mistaken and so on. If it carries on like this, the Soviet Union may one day risk a free press. Meanwhile, one consequence cannot but be a beneficial access of civility. Further ahead is the prospect of the mutual stimulus that will come from allowing two separate intellectual commmunities to rub shoulders with each other.

\section{Realism}

Elsewhere, the auguries are also not so bad. Realism seems to be back in fashion. The lofty detachment with which the US administration has dealt with the Congress for the past six years will be transformed, now that the Democrats control the Senate, into a process by which the two sides reach an accommodation by familiar bargaining. The new Congress could well be able to make the point that a workable agreement on strategic arms would be preferable to the preservation of planned spending on the Strategic Defense Initiative; the case will be easier to make now that the administration has been convicted of naivety in its dealings with Iran. The other side of this coin is that the Congress will be in no mood to control its spending in the two years preceding the next presidential election, so that a substantially shrunken federal deficit is a poor prospect; that matters because the present state of affairs in which the United States is sustained by borrowing from abroad cannot last much longer. The new Congress will be more eager than its predecessor, and probably more successful, at enacting short-term protectionist palliatives but, luckily, it seems now to have sunk home that righting the economic imbalance between the United States and the rest of the world requires reform of the educational system at all levels. That cannot but be good for scholarship and research.

\section{Problem}

Japan, the chief financier of the US trade deficit, is the image in this looking-glass. Superficially, the problem for Japan is how to spend all the wealth its companies have earned in the world's export markets. Individuals will not change their ways, but will carry on saving. Companies, feaful that their export trade may be grinding to a halt, are busily and ingeniously tunnelling beneath the now-high yen, building factories overseas. The year ahead could be that in which people elsewhere who now acknowledge that they owe their video-recorders to Japan must also learn to thank Japanese companies for their jobs. The absorbing question is whether one outcome will be the long overdue reform of the Japanese universities. Another is whether Japan will realize its ambition of making a decisive contribution to basic science. It is a sign of grace that these have become political goals.

Europe (see p. 8) is less confident. The management of the European Communities repeatedly perplexes those who grapple with the task. But national politicians have made a useful start on dealing with the recurring agricultural surpluses. They are also beginning to realize what they should have known 30 years ago, that there is no point in belonging to a common market if public purchases are still made chauvinistically; there should be some progress on that front this year. The European Commission's frustration that its ambitions for Community research have not been denied but simply ignored, by the cancellation of last month's planned meeting of research ministers, is understandable but beside the point. It is more important that some member states, even poor Britain for example (see p. 5), have come round to believing that the way forward entails the more deliberate harnessing of innovation to survival, economic and otherwise. These days, after all, it is a luxury to believe that a recipe that may work. Would that there were such a one for, say Africa. Japan's New Year loan of $\$ 9,000$ million to this international aid agencies will help, but only as a palliative. Selfsustainment is the crying need. 